\section{Separation of omphalopagus conjoined twins using combined caudal epidural - general anesthesia}

Purpose: To describe the anesthetic management of newborn omphalopagus conjoined twins undergoing a series of diagnostic and surgical procedures which culminated in successful separation at one month of age.

Clinical features: Evaluations of the extent of shared organ systems were carried out without the need for anesthesia. The twins were anesthetized twice, once for insertion of skin expanders, and later for surgical separation. Various airway management techniques were utilized. To facilitate surgical separation, caudal epidural catheters were inserted in an effort to provide both operative and post-operative analgesia. In addition, prior to the induction of anesthesia, the extent of cross-circulation between twins was assessed.

Conclusion: Caudal epidural catheters can be used to provide both operative and post-operative analgesia. Early extubation, another benefit of regional analgesia, was not achieved because both twins developed respiratory failure in the immediate postoperative period. Testing for the extent of cross-circulation between twins proved valuable, allowing for detailed scripting of the complex induction sequence and airway management.

Objectif : Décrire la prise en charge anesthésique de jumeaux siamois nouveau-nés, monomphaliens, séparés avec succès à l'âge d'un mois à la suite d'une série d'interventions diagnostiques et chirurgicales.

Éléments cliniques : Les mesures de limportance des systèmes organiques partagés ont pu être réalisées sans recourir à l'anesthésie. Les jumeaux ont été anesthésiés à deux reprises, pour l'insertion d'expanseurs cutanés et pour la séparation chirurgicale. On a utilisé différentes techniques pour le contrôle des voies respiratoires. Dans le but de faciliter la séparation chirurgicale, des cathéters caudaux ont été insérés pour assurer une analgésie opératoire et postopératoire. De plus, avant l'induction de l'anesthésie, l'ampleur de la circulation croisée entre les jumeaux a été évaluée.
Conclusion : Le cathéter caudal peut être utilisé pour fournir autant l'analgésie opératoire que postopératoire. L'extubation précoce, un autre avantage de l'analgésie régionale, n'a pas été réalisée parce qu'une insuffisance respiratoire s'est développée immédiatement immédiatement après /intervention chirurgicale. L'évaluation de l'ampleur de la circulation croisée a été précieuse en ce qu'elle a fournit une démarche structurée pour l'induction complexe et la maitrise des voies aériennes.

A LTHOUGH conjoined twins are a rare occurrence, several successful operative separations have been reported. ${ }^{1,3,4,6-9}$ To our knowledge, none of these reported operations have included regional anesthesia as part of the intraoperative anesthetic management or for postoperative analgesia. In addition, there are no reports of testing the extent of cross-circulation between conjoined twins to evaluate what might occur during the induction of anesthesia. We report the successful separation of omphalopagus conjoined twins using caudal epidural anesthesia with continuous infusion of local anesthetic for postoperative analgesia. We also tested for the extent of cross circulation between twins with both inhaled and $i v$ drugs, and suggest how that information can be used to plan the induction of anesthesia and management of the airway.

Case report

Male omphalopagus twins were delivered by Cesarean section at 36 weeks gestation. They needed no resuscitation at birth. The combined birth weight was $5600 \mathrm{~g}$ and they shared a single umbilical cord. They

From the Departments of Anesthesiology* †and Pediatric Surgerył, University of California at San Diego, California, USA. Address correspondence to: Dr. Mark Greenberg, Department of Anesthesiology, University of California, San Diego, UCSD Medical Center, 200 West Arbor Drive, San Diego, CA 92103-8770, USA. Phone: 619-543-1999; Fax: 619-542-5424; E-mail: mgreenbe@ucsd.edu Accepted for publication January 24, 2001. 


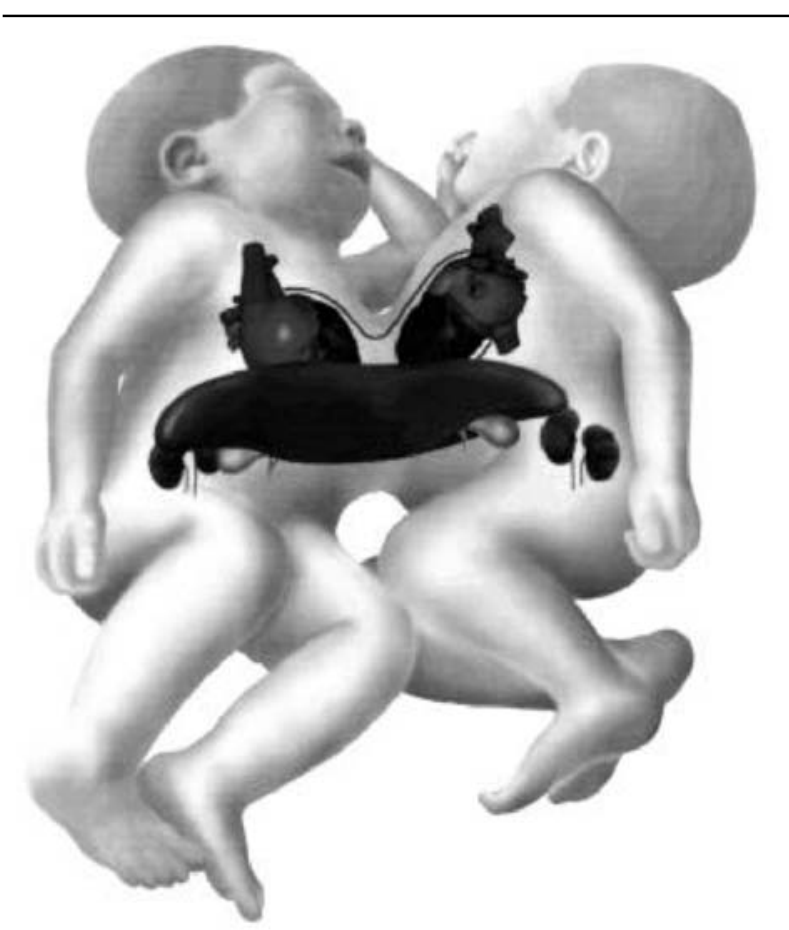

FIGURE 1 Omphalopagus conjoined twins positioned almost face-to-face and joined by an extensive tissue bridge which includes the liver. Note that the faces are not directly opposed. "Scissoring" the heads allowed for more room in which to manipulate airways.

were joined from the mid-thorax to the mid-abdomen (Figure 1).

Investigation of the gastrointestinal (GI) anatomy by upper GI study revealed two separate and normal alimentary tracts. Computed tomography (CT) scan of the chest and abdomen suggested two complete thoracic cavities, two independent sets of lungs, and two hearts sharing a single pericardial sac. There was substantial hepatic parenchymal connection, but there appeared to be two complete biliary systems and portal circulatory systems. The anatomy was otherwise normal in appearance. Ultrasound studies confirmed the cardiac anatomy described above, and also indicated two separate and normal renal systems. These studies were all done without the need for anesthesia.

An initial operation was performed at two weeks of age to insert tissue expanders to allow for skin closure of the anticipated extensive wound defects. Prior to induction of anesthesia we tested for cross circulation between twins. Glycopyrrolate was given intravenously to twin $B$ causing an immediate increase in heart rate. However, there was no change in twin A's heart rate for a five-minute interval following the administration of the glycopyrrolate. With no evidence of cross circulation between the twins, we felt it unlikely that twin A would become apneic shortly after drug administration to twin $\mathrm{B}$. In addition, the dose of water-soluble drugs could be based on the weight of each twin individually, rather than the total weight.

With this knowledge, an ip induction technique was planned. After establishing functional iv lines in each baby, they were positioned to optimize laryngoscopy of twin B. To do this, twin B was placed supine and twin $\mathrm{A}$ was supported in such a manner that the space above the face of twin $B$ was unobstructed. Twin B was given propofol and vecuronium intravenously. Direct laryngoscopy was unremarkable, and the baby's trachea was easily intubated. During this time, twin A required some minimal restraint to prevent interference with the direct laryngoscopy and did not appear to be effected by the drugs given to twin B. Anesthesia was then induced in twin A in a similar fashion. The tissue expanders were placed uneventfully and the babies were extubated in the nursery on postoperative day one.

Surgical separation was undertaken at 33 days of age. For logistical reasons, it was decided to perform endotracheal intubation and insert the arterial and central venous lines the day prior to surgery. The babies were sedated with meperidine and nasotracheally intubated using a fiberoptic bronchoscope. After endotracheal intubation, each baby was sedated and given muscle relaxants. Arterial and central venous catheters were then placed in the radial and internal jugular vessels, respectively.

The next morning, the infants were transported to the operating room, where blood pressure, EKG, temperature, and $\mathrm{SpO}_{2}$ monitors were affixed to each infant. In order to prevent confusion, all the monitoring cables, arterial and venous lines, and anesthesia machine hoses were color-coded. Each baby had his own monitoring system and they were placed in the lateral position on two operating room tables that were pushed and locked together. All this was done to facilitate ease of separation and allow the surgeons to continue working on both babies without the need to move to another operating room.

Caudal epidural catheters were inserted in each baby and a test dose of $1 \mathrm{ml}$ of $1 \%$ lidocaine with 1:200,000 epinephrine was administered. There was no evidence of either intravascular or intrathecal misplacement. Bupivicaine, $3 \mathrm{ml}$ of $0.25 \%$, was given to each twin and supplemented approximately every 90 min. There was no hemodynamic response to the initial incision. Isoflurane $0.4 \%$, nitrous oxide $60 \%$, and 
fentanyl $3 \mu \mathrm{g} \cdot \mathrm{kg}^{-1}$ (total intraoperative dose) were used to provide general anesthesia during the operative procedure itself.

Prior to incision we tested for transfer of isoflurane from one twin to the other. End-tidal isoflurane was held at $1 \%$, as measured by mass spectroscopy, in one twin. There was no measurable expired isoflurane from the other twin during this $15 \mathrm{~min}$ observation period.

The division of the thorax was completed first. The thoracic cavities, then the pericardium, were divided with minimal blood loss. Next the liver was separated using electrocautery and an argon beam coagulator. During this portion of the procedure there was significant blood loss (total of $400 \mathrm{ml}$ ). Transfusion of packed red blood cells and infusion of dopamine were required to maintain the blood pressure during this time. Finally, the remainder of the abdominal wall was divided, the babies were separated, and the operating tables were moved apart. After removal of the skin expanders, the wounds were closed without undue tension. The babies were transferred back to the neonatal intensive care unit in stable condition.

Following the procedure, both babies developed respiratory failure $\left(\mathrm{PaO}_{2}<70 \mathrm{mmHg}\right.$ with an $\mathrm{F}_{1} \mathrm{O}_{2}$ $>70 \%$ ) requiring aggressive mechanical ventilatory support. Twin A was treated with high-frequency oscillatory ventilation (HFOV) for 24 hr but was subsequently weaned and extubated on postoperative day five. Twin B also had difficulty with oxygenation and ventilation, and was placed on HFOV and inhaled nitric oxide with a good response. He was extubated on the fourth postoperative day. While the babies remained intubated a fentanyl infusion was used for sedation. They also received epidural lidocaine infusions of $1 \mathrm{mg} \cdot \mathrm{kg}^{-1} \cdot \mathrm{hr}^{-1}$ to provide analgesia. Serum lidocaine was measured daily, and remained below toxic concentrations (greater than $5 \mu \mathrm{g} \cdot \mathrm{ml}^{-1}$ ) throughout. The infusions were continued until the fifth postoperative day. There were no complications related to the epidural catheter or infusion. Both babies ultimately fed well, gained weight, and were discharged from the ICU on postoperative day ten.

\section{Discussion}

We have described the successful separation of omphalopagus conjoined twins using a combined caudal epidural and general anesthesia technique. Two points about their preoperative management deserve discussion. If the babies can be kept calm, anesthesia may not be needed for diagnostic studies. If anesthesia is required, the babies should probably be intubated as has been previously described for conjoined twins requiring a magnetic resonance imaging scan. ${ }^{4}$ There

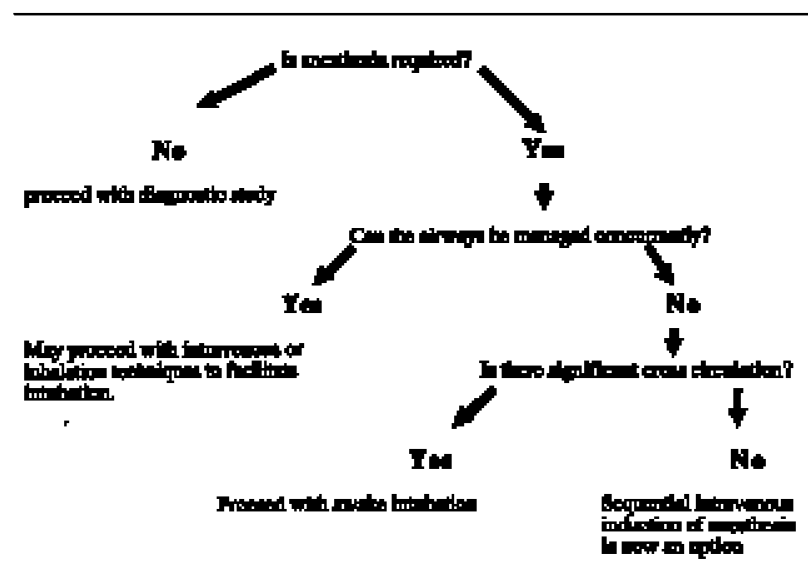

FIGURE 2 Determining the extent of cross circulation provides information that can be used to plan the induction of anesthesia. If anesthesia is required for a diagnostic or surgical procedure it must first be determined if both babies can be mask ventilated with confidence. If not, sequential induction can be performed only if there is little or no cross circulation between babies.

Otherwise, awake intubation, with or without fiberoptic assistance, may be required.

are three reasons to do this. First, the amount of room available to manipulate the airways may be severely limited, making it more difficult to mask ventilate effectively or perform laryngoscopy. Second, if laryngoscopy and intubation are required, they must be done on a sequential basis, thus prolonging the interval from the initial intervention to the second successful endotracheal intubation. Lastly, being in the radiology suite may magnify the logistical difficulties of managing two babies with airway difficulties at once. Laryngeal mask airways are an attractive alternative for these situations, and may be suitable for emergency airway management. However, in this case, anesthesia was not needed at all for these diagnostic procedures.

Prior to the initial surgery (placement of skin expanders) we determined that there was no significant cross circulation. We were able to take advantage of this in two ways. First, we could proceed with sequential $i v$ inductions without significant time constraint and with a low probability of being responsible for controlling ventilation in both twins at the same time (Figure 2). This avoided us the need to ventilate one twin while trying to perform laryngoscopy on the other, an important consideration given the limited manoeuvring room available. Second, we were able to calculate drug dose based on the weight of each individual twin rather than on the combined weight. 
Although CT scanning showed no apparent vascular connection, circulatory patterns can vary from minute to minute and be missed during a contrast study. ${ }^{2,7}$ For this reason, iv testing of the extent of cross circulation is necessary. Glycopyrrolate was chosen because of its relatively high water solubility, thus serving as a model for other water-soluble drugs, such as the muscle relaxants. Atropine would also have provided the desired antisialogogue effects while testing the extent of cross circulation. An interesting correlation was the observation that each twin responded independently to surgical stimulus. Since the isoflurane did not cross over from one twin to the other, it was apparent that each twin needed to be treated as a separate entity even before physical separation.

We could have performed awake intubation in each twin, but adverse effects have been described. ${ }^{1}$ These include coughing and straining leading to hemodynamic changes in the other twin occurring during awake laryngoscopy. For older conjoined twins, awake intubation may not be an attractive option. For the surgical separation itself, nasotracheal intubation was chosen to optimize fixation of the endotracheal tubes as it was expected that the babies would be repositioned several times during the course of this procedure. A fiberoptic technique was chosen as it was felt that it would be easier to perform nasotracheal intubation this way.

Caudal epidural anesthesia and postoperative analgesia has been used successfully in neonatal surgeries such as repair of tracheoesophageal fistulae, diaphragmatic hernia, and gastroschisis. ${ }^{10}$ Purported benefits include a decrease in the stress response and decreased opioid and anesthetic requirements, both facilitating earlier tracheal extubation and improved postoperative pulmonary function. Finding that there was no published evidence that vertebral malformations were any more common in omphalopagus conjoined twins than the general population, caudal epidural catheters were placed in hopes of achieving these specific goals. While the caudal route is associated with a greater incidence of bacterial colonization of the catheter tip ${ }^{11}$ than lumbar epidural catheters, we felt that the caudal approach allowed for more precise positioning of the tip of the catheter. Precise catheter positioning is important because we prefer to infuse local anesthetics rather than narcotics in neonates. Our local anesthetic of choice for infusion into the epidural space is $0.1 \%$ lidocaine at a rate of $1 \mathrm{mg} \cdot \mathrm{kg}^{-1} \cdot \mathrm{hr}^{-1}$ (l $\left.\mathrm{ml} \cdot \mathrm{kg}^{-1} \cdot \mathrm{hr}^{-1}\right)$. We chose lidocaine rather than bupivicaine because this allowed us to easily monitor serum lidocaine concentrations and be alerted to possible toxic accumulation of local anesthetic.
In this case we were successful in decreasing the amount of inhaled and iv drugs given during the operative procedure, as shown by the requirement for only amnestic concentrations of isoflurane and negligible doses of fentanyl. However, because of hypoxemic respiratory failure requiring HFOV in both twins and nitric oxide therapy in twin $\mathrm{B}$, the full benefits of regional analgesia were never realized. Given the use of in fentanyl during the time the babies were intubated, it was impossible to objectively judge the effectiveness of the epidural analgesia alone in providing analgesia. However, it is our unsubstantiated belief that the regional analgesia was helpful in facilitating the eventual tracheal extubation. It is also unclear whether or not the epidural had an impact on reducing the overall stress response to surgery.

The cause of the respiratory failure remains unknown but has been reported in other conjoined twin separations. ${ }^{2,6,9}$ It may have been due to an inflammatory process triggered by extensive surgical manipulation including those required for separation of the liver.

In conclusion, we have shown that separation of conjoined twins using combined epidural and general anesthesia is feasible. We also recommend screening for the extent of cross circulation between twins prior to $i v$ induction and direct laryngoscopy. If there is any doubt as to whether intubation may be difficult for any reasons such as unfavourable airway features or in how the twins are joined, nasotracheal intubation over a fiberoptic bronchoscope is also a viable option.

\section{References}

1 Hoshina H, Tanaka O, Obara H, Iwai S. Thoracopagus conjoined twins: management of anesthetic induction and postoperative chest wall defect. Anesthesiology 1987; 66: 424-6.

2 Bloch EC, Karis JH. Cardiopagus in neonatal thoracopagus twins: anesthetic management. Anesth Analg 1980; 59: 304-7.

3 Furman EB, Roman DG, Hairabet J, Yokoyama $M$, Carmona $R$ Management of anesthesia for surgical separation of newborn conjoined twins. Anesthesiology 1971; 34: 95-101.

4 Sury MRJ, Brown JL, Aitken K Anaesthesia for conjoined twins during magnetic resonance imaging. Europ J Anaesth 1994; 11: 139-42.

5 Diaz JH, Furman EB. Perioperative management of conjoined twins. Anesthesiology 1987; 67: 965-73.

6 Roy $M$. Anaesthesia for separation of conjoined twins. Anaesthesia 1984; 39: 1225-8.

7 Harrison VL, Keneally JP, Gold PD, Malcom PS, Overton JH Anaesthesia for separation of conjoined 
twins in the neonatal period. Anaesth Intensive Care $1985 ; 13: 82-5$.

8 Georges LS, Smith KW, Wong KC Anesthetic challenges in separation of craniopagus twins. Anesth Analg 1987; 66: $783-7$.

9 Chao C-C, Susetio L, Lun K-W, Kwan W-F. Anaesthetic management for successful separation of tripus ischiopagal conjoined male twins. Can Anaesth Soc J $1980 ; 27: 565-70$.

10 Desparmet JF. Central blocks in children and adolescents. In: Schechter NL, Berde CB, Yaster M, (Eds). Pain in Infants, Children, and Adolescents. William and Wilkens Publishers, 1993: 245-60.

11 McNeely JK, Trentadue NC, Rusy LM, Farber NE. Culture of bacteria from lumbar and caudal epidural catheters used for postoperative analgesia in children. Reg Anesth 1997; 22: 428-31. 